\title{
The cost of surgical training: analysis of operative time for laparoscopic cholecystectomy
}

\author{
M. von Strauss und Torney $\cdot$ S. Dell-Kuster • \\ R. Mechera $\cdot$ R. Rosenthal $\cdot$ I. Langer
}

Received: 11 October 2011/Accepted: 28 February 2012/Published online: 5 April 2012

(C) Springer Science+Business Media, LLC 2012

\begin{abstract}
Background Duration of surgery is a main cost factor of surgical training. The purpose of this analysis of operative times for laparoscopic cholecystectomies (LC) was to quantify the extra time and related costs in regards to the surgeons' experience in the operating room (OR).

Methods All LC performed between January 01, 2005 and December 31, 2008 in 46 hospitals reporting to the database of the Swiss Association for Quality Management in Surgery (AQC) were analyzed $(n=10,010)$. Four levels of seniority were specified: resident (R), junior consultant (JC), senior consultant (SC), and attending surgeon (AS). The differences in operative time according to seniority were investigated in a multivariable log-linear and median
\end{abstract}

This study was presented in part at the annual meeting of the Swiss Society of Surgery, Geneva, Switzerland, May 2011.

Electronic supplementary material The online version of this article (doi:10.1007/s00464-012-2236-1) contains supplementary material, which is available to authorized users.

M. von Strauss und Torney $(\bowtie) \cdot S$. Dell-Kuster .

R. Mechera - R. Rosenthal

Department of Surgery, Basel University Hospital,

Spitalstrasse 21, 4031 Basel, Switzerland

e-mail: mvonstrauss@uhbs.ch

M. von Strauss und Torney $\cdot$ R. Mechera

Department of Surgery, Cantonal Hospital Bruderholz,

4041 Bruderholz, Switzerland

\section{S. Dell-Kuster}

Institute for Clinical Epidemiology and Biostatistics, Basel

University Hospital, Basel, Switzerland

I. Langer

Department of Surgery, Lindenhof Hospital Bern,

4031 Bern, Switzerland regression analysis controlling for possible confounders. The OR costs were calculated by using a full cost rate in a teaching hospital.

Results A total of 9,208 LC were available for analysis; 802 had to be excluded due to missing data $(n=212)$ or secondary major operations $(n=590)$. Twenty-eight percent of the LC were performed by $\mathrm{R}$ as teaching operations $(n=2,591)$. Compared with $\mathrm{R}$, the multivariable analysis of operative time showed a median difference of $-2.5 \mathrm{~min}$ $(-9.0 ; 4.8)$ for JC and $-18 \min (-25 ;-11)$ for SC and $-28 \min (-35 ;-10)$ for AS, respectively. The OR minute costs were $€ 17.57$, resulting in incremental costs of $€ 492$ $(159 ; 615)$ per operation in case of tutorial assistance.

Conclusions The proportion of LC performed as tutorial assistance for R remains low. Surgical training in the OR causes relevant case-related extra time and therefore costs.

Keywords Cholecystectomy · Education . Costs $<$ Technical $\cdot$ Training $<$ Endoscopy

During the past decade, several western countries have changed their organization of medical services. Former payment by daily rates has been abandoned in favor of case-related allowances (diagnosis-related groups). Switzerland is currently one of the last countries to follow this pathway. An unsolved issue in this setting is funding of graduate medical training and surgical training particularly under these new circumstances [1].

Even in the United States, where a system of reimbursement of direct and indirect training costs via direct and indirect graduate medical education payments (DGME and IDGME) mainly funded by Medicaid and Medicare dates back to 1965 , there is ongoing debate about trainingrelated costs in surgical specialties [2-4]. 
In countries without reimbursement for training expenses, such as Switzerland or Germany, it is a common belief that surgical residents "pay" for their education by taking care of surgical wards or during their unsupervised activities at different levels of seniority [5]. Some authors assume that running wards and emergency rooms only with faculty staff would raise general healthcare costs dramatically, leading to the idea of whether employing doctors in training is even profitable if the latter cause training-related extra costs and therefore accounting for the cost efficiency of the current educational model in these countries. On the other hand, a rising number of private institutions are profitably managed without employing residents. This may be the result of patient selection or better resource allocation.

Independently of the model of reimbursement (lower wages or funding by public institutions), a main cost factor in surgical training is operative time. Several single-institution studies have shown that surgical training is timeconsuming and therefore costly due to extra time in the operating room (OR) [2, 6-12]. Additionally, the recent reduction in resident working hours $(80 \mathrm{~h}$ weekly in the United States or $50 \mathrm{~h}$ in Switzerland) without cutting wages proportionally resulted in the medical workforce becoming remarkably more expensive [13-15].

In contrast to the Anglo-American scope, in Switzerland, Germany, and Austria, there are no registered residency programs. Surgical training is taking place (or not taking place) during the first 6 to 8 years after graduation. During this time, operative exposure is unsteady and interrupted by nonoperative rotations to emergency wards, intensive care units, or as ward surgeon for other specialities. Only briefly before specialization, some applicants achieve a status comparable to a chief resident spending more time in the OR. This has implications for learning curves for standard operations on the level of resident or junior consultant and also was the subject of this investigation. To our knowledge, no study has been published to compare operative times of surgeons with different levels of seniority under the aspect of training and resulting costs on a large, multicenter basis.

In the database of the Swiss Association for quality management in surgery (AQC), patient and operative data are recorded for the purpose of quality assurance and benchmarking. Currently, 52 public and private surgical departments and practices are reporting anonymized data to the database. The database is monitored and certified by the Swiss Federal Commissioner for Data Protection.

The purpose of our study was to evaluate the time differences in the duration of the indicator operation laparoscopic cholecystectomy (LC) between surgeons with different levels of seniority while controlling for confounders (primary objective) and to estimate the resulting extra costs as well as the proportions of LC performed as tutorial assistance (secondary objectives).

\section{Materials and methods}

All LC documented in the database of the AQC from January 1, 2005 until December 31, 2008 were analyzed. Forty-six of 52 hospitals performed LC.

Database and patient selection

The database included 10,010 patients; 590 patients had to be excluded because they underwent an additional surgical intervention during the same anesthesia. Also, 157 patients with missing operative time and 45 patients with unrealistically short or long operative times $(<20 \mathrm{~min}(n=22)$ or $<30 \mathrm{~min}$ in combination with an intraoperative cholangiography $(n=13)$ or $>270 \min (n=10))$ were excluded. Children younger than age 16 years were discarded $(n=10)$. A total of 9,208 patients remained for the baseline table (Fig. 1; Table 1). For the models, only complete cases were taken into consideration, leaving 9,045 patients for the uni- and multivariable analyses.

The data were screened for any systematic pattern of missingness by examination of the association between missingness and the predictors or the outcome, respectively. Imputation of missing values in the covariates of interest was omitted because of the rather low number of

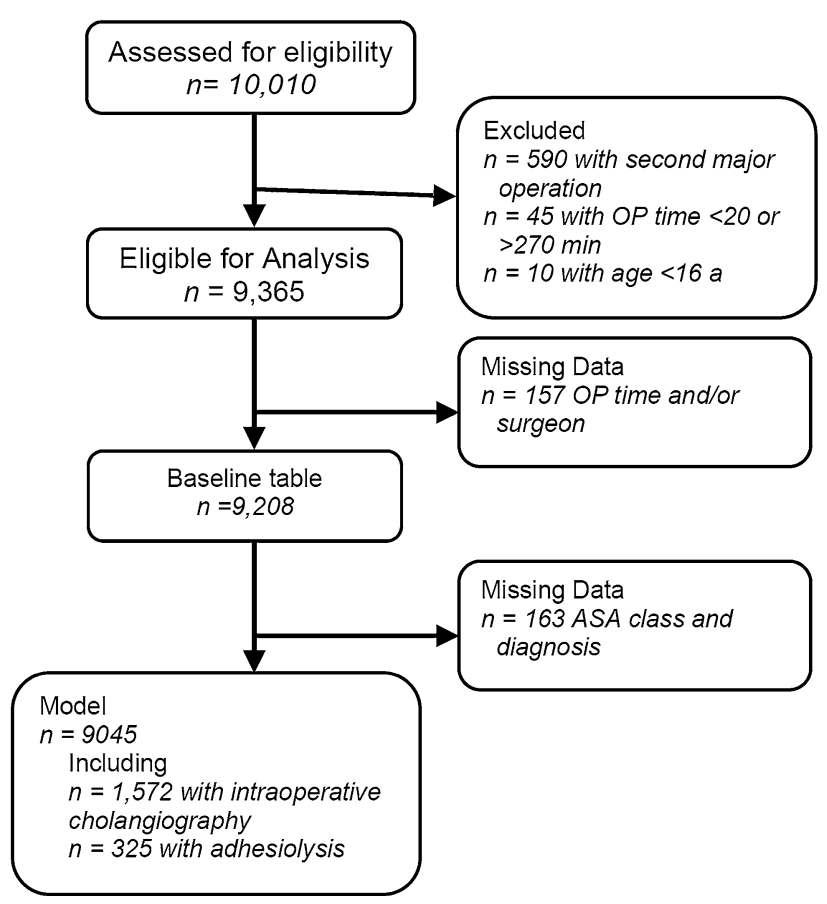

Fig. 1 Flow of patients in- and excluded in the analysis 
Table 1 Patient and procedure characteristics

\begin{tabular}{|c|c|c|}
\hline & $\begin{array}{l}\text { All } \\
(n=9,208)\end{array}$ & $\begin{array}{l}\text { Missing [count } \\
\text { (\% of all)] }\end{array}$ \\
\hline Age, mean (SD) & $54(16)$ & $5(0.1 \%)$ \\
\hline Gender & & $25(0.3 \%)$ \\
\hline Female & $5,586(61 \%)$ & \\
\hline Male & $3,597(39 \%)$ & \\
\hline ASA & & $70(0.8 \%)$ \\
\hline I & $3,355(36 \%)$ & \\
\hline II & $4,771(52 \%)$ & \\
\hline III & $907(10 \%)$ & \\
\hline IV & $83(0.9 \%)$ & \\
\hline $\mathrm{V}$ & $22(0.2 \%)$ & \\
\hline Experience of surgeon & & $3(0.03 \%)$ \\
\hline Resident & $2,591(28 \%)$ & \\
\hline Junior consultant & $2,625(29 \%)$ & \\
\hline Senior consultant & $3,463(38 \%)$ & \\
\hline Attending surgeon & $526(5.7 \%)$ & \\
\hline Mode of surgery & & $7(0.1 \%)$ \\
\hline Elective & $6,789(74 \%)$ & \\
\hline Emergency & $2,412(26 \%)$ & \\
\hline Type of insurance & & $599(6.5 \%)$ \\
\hline Compulsory & $5,573(61 \%)$ & \\
\hline Semi-private & $1,516(16 \%)$ & \\
\hline Private & $1,520(17 \%)$ & \\
\hline Type of institution & & - \\
\hline Public & $8,455(92 \%)$ & \\
\hline Private & $753(8.2 \%)$ & \\
\hline Indication for surgery & & $78(0.9 \%)$ \\
\hline Noninflammatory & $4,593(50 \%)$ & \\
\hline Inflammatory & $4,395(48 \%)$ & \\
\hline Others & $142(1.5 \%)$ & \\
\hline Intraoperative cholangiography & & - \\
\hline No & $7,654(83 \%)$ & \\
\hline Yes & $1,554(17 \%)$ & \\
\hline Intraoperative adhesiolysis & & - \\
\hline No & $8,887(97 \%)$ & \\
\hline Yes & $321(3.5 \%)$ & \\
\hline Time of surgery & & $2593(28 \%)$ \\
\hline Daytime (7 am-7 pm) & $6,346(69 \%)$ & \\
\hline Night time (7 pm-7 am) & $269(2.9 \%)$ & \\
\hline Intraoperative complications* & & $65(0.7 \%)$ \\
\hline None & $9,091(99 \%)$ & \\
\hline Mild & $28(0.3 \%)$ & \\
\hline Medium & $23(0.3 \%)$ & \\
\hline Severe & $1(0.001 \%)$ & \\
\hline
\end{tabular}

*Based on the surgeon's estimation

Admissions for LC from January 1, 2005-December 31, 2008 to 46 different hospitals missing values ( $<1 \%$ except for insurance class). Imputation of the outcome was not performed, because it would not provide any new information on the relationship of predictors with the outcome and is therefore generally not useful for the purpose of better estimation of regression coefficients [16].

Definitions of seniority of the operating and assisting surgeon

Four levels of seniority were defined:

- Resident as called in the setting of the study "Assistenzarzt" is a medical doctor after graduation from medical school and before board certification.

- Junior Consultant as called in the setting of the study "Oberarzt" is a surgeon after board certification sometimes employed as a fellow for further specialization.

- Senior Consultant as called in the setting of the study "Leitender Arzt oder Chefarzt" is a board-certified surgeon with further subspecialization and who is a faculty member.

- Attending Surgeon as called in the setting of the study "Belegarzt" is a board-certified surgeon with a private practice who is not employed by the hospital itself but operates patients for a fee in private or public institutions.

Statistical analysis

All analyses and graphs were performed using Intercooled Stata Version 11.0 for Macintosh (StataCorp, College Station, TX, USA).

The data were modelled in a log-linear regression model due to the right-skewed distribution of operative time. Additionally, a median regression model was performed to calculate easily the operating time for any combination of covariates. The estimates of the experience level of the surgeon on operating time were adjusted for the following possible confounders: age, gender, ASA classification, mode (elective vs. emergency) and indication of surgery, and whether an intraoperative cholangiography and/or adhesiolysis had taken place. In both models, the cluster effect of operations performed at the same hospital (centers) was taken into account. As a sensitivity analysis, the effect of further covariates, such as intraoperative complications, insurance class, and clinic status (private vs. public) was investigated.

Operating room costs

The cost per minute for the OR was calculated by a full cost analysis for a middle-sized nonacademic teaching 
hospital. The data for the cost analysis were provided by the accountancy of the hospital. For the surgeons' costs, monthly wages of residents and junior consultants were scaled down to wage rates per minute. For senior consultants and attending surgeons, salaries are generally highly variable and a result of individual contract negotiations. Moreover, this staff underlies no compulsory working hour restrictions. We therefore included a range of possible yearly gratifications and three different average weekly working hours. The resulting wages also were scaled down per minute.

The cost unit "operating room," which includes the personnel expenses for operating nurses and other staff (including cleaner) as well as maintenance costs (singleuse equipment, depreciation of buildings, and running expenses, such as electricity), is yearly being recorded and divided by the overall operative time in the hospital (sum of all incision to suture times) and also was scaled down per minute. The cost unit "anesthesia" includes all expenses for personnel (doctors and nurses), depreciation for respirators and other devices, as well as expandable materials and was likewise scaled down per minute. Compared with these data from the reference hospital, the accountancy of a university hospital supplied data on minute costs in this institution.

The resulting overall cost per minute was multiplied with the average additional operative time for teaching surgery. To offer additional information on the impact of higher gratifications for SC or AS, we considered a range of yearly gratifications for this staff compared with R and JC.

\section{Results}

\section{General characteristics}

Patient and procedure characteristics (including reporting on missing data) are displayed in Table 1 . The male to female ratio was approximately 2:3. Twenty-eight percent of all patients were operated on by residents, whereas junior consultants, senior consultants, and attending surgeons accounted for 29, 38 and $5.7 \%$ of the operations, respectively. Three quarters of the operations were electively scheduled; $61 \%$ of the patients had compulsory basic health insurance. Patients were mainly treated in public institutions (92\%). Inflammatory and noninflammatory disease accounted for approximately half of the indications each. Intraoperative cholangiography was performed in $17 \%$ of the operations. The analysis of median operative times by level of surgeon's seniority showed $80 \mathrm{~min}$ for residents and junior consultants and $60 \mathrm{~min}$ for senior consultants. Attending surgeons had a median operative time of $56 \mathrm{~min}$. These results are displayed in
Fig. 2. A detailed table of patient characteristics by level of surgeons' seniority is displayed in the Electronic supplementary material of this publication.

\section{Log-linear regression analysis}

The results of univariate and multivariable analysis with $95 \%$ confidence intervals are displayed as relative measures after back-transformation in Table 2 and Fig. 3. Compared with the operative time of the resident (reference), an approximate decrease of $21 \%(p<0.001)$ in operative time was found for senior consultants and $34 \%(p<0.001)$ for attending surgeons respectively in the multivariable analysis. There was no significant difference between junior consultants and residents concerning operative time.

\section{Median regression analysis}

To quantify the time difference in absolute numbers for time cost analysis, median operative times were analyzed. As in univariate analysis of operative times, there was no significant difference in multivariable analysis between residents and junior consultants. Senior consultants had $18 \mathrm{~min}$ and attending surgeons $28 \mathrm{~min}$ shorter operative times. The results of univariate and multivariable analysis are displayed in Table 3. Including other possible confounders (i.e., intraoperative complications, insurance class, and clinic status) in a sensitivity analysis did not change the point estimates of the influence of the experience level nor their $95 \%$ confidence intervals (output not shown).

\section{OR costs}

The reference hospital for calculation of minute costs for the OR was a midsize nonacademic teaching hospital with 430 beds and an average of 12,900 inpatient cases per year (approximately 2,500 surgical inpatients per year). The minute costs for the surgeons as determined by average monthly salaries of a resident (CHF8,532 (€5373)) and junior consultant (CHF12,698 (€7997)) and the compulsory $50 \mathrm{~h}$ workweek amounted to CHF0.71 for a resident and CHF1.055 for a junior consultant. Based on the assumption that a cholecystectomy is performed by two surgeons, this resulted in CHF1.765 CHF/per minute.

For SC and AS, a review in the reference hospital showed that yearly gratifications range from CHF150,000 $(€ 94,470)$ to CHF500,000 (€314,901). Considering average weekly working hours of this staff ranging from 60 to $80 \mathrm{~h}$, the resulting minute costs for this staff ranges from CHF0.68 to CHF3.01. Based on the assumption that the LC is performed by one of these staff members and a $\mathrm{R}$ or rarely a JC, the minute costs range from $\mathrm{CHF} 1.39$ to 3.72 
with $\mathrm{R}$ as first assistant or CHF1.74 to CHF4.02 with JC as first assistant. The costs for anesthesia were CHF7.47 per minute, including all expenses for personnel and supplies.

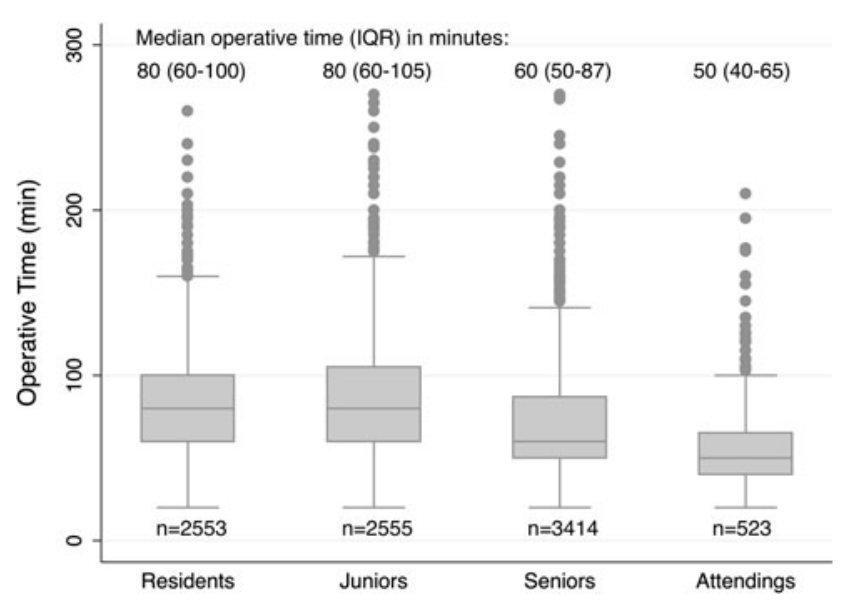

Fig. 2 Median operative times for all LC $(n=9,045)$ according to the level of seniority
The personnel expenses for operating nurses and other staff (including cleaner and others) as well as maintenance costs (single-use equipment, depreciation of buildings, and

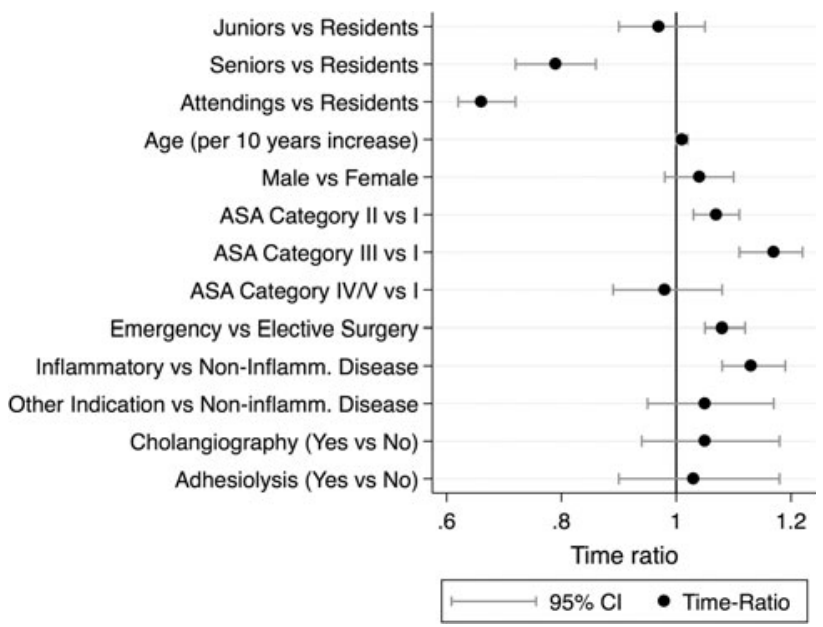

Fig. 3 Multivariable analysis of operative time (log-transformed) and influence of different confounders

Table 2 Univariate and multivariate linear regression analysis for operating time $(n=9,045)$ using robust standard errors to adjust for clustering in 46 different clinics

\begin{tabular}{|c|c|c|c|c|}
\hline \multirow[t]{2}{*}{ Covariates } & \multicolumn{2}{|l|}{ Univariate analysis } & \multicolumn{2}{|l|}{ Multivariate analysis } \\
\hline & Exp. coefficient $\left(\mathrm{e}^{\beta}\right)^{*}(95 \% \mathrm{CI})$ & $p$ value & Exp. coefficient $\left(\mathrm{e}^{\beta}\right)^{*}(95 \% \mathrm{CI})$ & $p$ value \\
\hline \multicolumn{5}{|c|}{ Experience of surgeon: resident $=$ reference } \\
\hline Junior consultant & $1.01(0.93 ; 1.09)$ & 0.86 & $0.97(0.9 ; 1.05)$ & 0.46 \\
\hline Senior consultant & $0.81(0.74 ; 0.88)$ & $<0.001$ & $0.79(0.72 ; 0.86)$ & $<0.001$ \\
\hline Attending surgeon & $0.67(0.62 ; 0.73)$ & $<0.001$ & $0.66(0.62 ; 0.72)$ & $<0.001$ \\
\hline \multicolumn{5}{|l|}{ Age } \\
\hline Per 10 years increase & $1.02(1.01 ; 1.03)$ & $<0.001$ & $1.01(1 ; 1.02)$ & 0.029 \\
\hline \multicolumn{5}{|l|}{ Gender } \\
\hline Male vs. female & $1.07(1.01 ; 1.14)$ & 0.027 & $1.04(0.98 ; 1.1)$ & 0.191 \\
\hline \multicolumn{5}{|c|}{ ASA classification: ASA I $=$ reference } \\
\hline ASA II & $1.11(1.07 ; 1.15)$ & $<0.001$ & $1.07(1.03 ; 1.11)$ & 0.001 \\
\hline ASA III & $1.24(1.18 ; 1.30)$ & $<0.001$ & $1.17(1.11 ; 1.22)$ & $<0.001$ \\
\hline ASA IV and V & $0.95(0.82 ; 1.10)$ & 0.479 & $0.98(0.89 ; 1.08)$ & 0.641 \\
\hline \multicolumn{5}{|l|}{ Mode of surgery } \\
\hline Emergency vs. Elective & $1.17(1.12 ; 1.22)$ & $<0.001$ & $1.08(1.05 ; 1.12)$ & $<0.001$ \\
\hline \multicolumn{5}{|c|}{ Indication for surgery: noninflammatory $=$ reference } \\
\hline Inflammatory & $1.16(1.12 ; 1.21)$ & $<0.001$ & $1.13(1.08 ; 1.19)$ & $<0.001$ \\
\hline Others & $1.1(0.99 ; 1.23)$ & 0.067 & $1.05(0.95 ; 1.17)$ & 0.328 \\
\hline \multicolumn{5}{|c|}{ Intraoperative cholangiography } \\
\hline Yes vs. no & $1.11(0.99 ; 1.24)$ & 0.081 & $1.05(0.94 ; 1.18)$ & 0.362 \\
\hline \multicolumn{5}{|l|}{ Intraoperative adhesiolysis } \\
\hline Yes vs. no & $0.99(0.86 ; 1.14)$ & 0.915 & $1.03(0.9 ; 1.18)$ & 0.658 \\
\hline
\end{tabular}

*Exponentiated coefficients given to make the interpretation easier, e.g., 0.79 becomes the factor by which the median operating time should be multiplied comparing cholecystectomies performed by a senior consultant and a resident respectively. Cholecystectomies performed by senior consultants seem to show a $21 \%$ shorter operating time than by residents; on the other hand, 1.07 corresponds to a $7 \%$ prolongation in median operating time comparing cholecystectomies performed in ASA II versus ASA I patients 
running expenses, such as electricity) were CHF18.66 per minute, resulting in CHF26.3/min without the operating surgeon. Compared with the data from the university hospital results in CHF 33.06 without the operating surgeons and therefore almost $25 \%$ higher costs/minute.

Accruing all costs of the reference hospital, this resulted in costs of CHF27.90 (€17.57) per minute for the operating room for JC and R as operating surgeons. For SC or AS as operating surgeons, the minute costs range from CHF27.52 to $\mathrm{CHF} 30.15$ ( $€ 17.33$ to $€ 18.99)$.

Taking the median operative time of the resident as a reference, an equivalent operation by an attending surgeon

Table 3 Multivariable median regression analysis for operating time $(n=9,045)$ adjusting for clustering effect of 46 clinics bootstrapped SE with 100 bootstrap samples; Percentile $95 \%$ CIs

\begin{tabular}{|c|c|c|}
\hline \multirow[t]{2}{*}{ Covariates } & \multicolumn{2}{|l|}{ Multivariate analysis } \\
\hline & $\begin{array}{l}\text { Median difference } \\
(\min )\end{array}$ & $95 \% \mathrm{CI}$ \\
\hline \multicolumn{3}{|c|}{ Experience of surgeon: resident $=$ reference } \\
\hline Junior consultant & -2.5 & $-9.0 ; 4.8$ \\
\hline Senior consultant & -18 & $-25 ;-11$ \\
\hline Attending surgeon & -28 & $-35 ;-10$ \\
\hline \multicolumn{3}{|c|}{ Age: mean age of 54 years $=$ reference } \\
\hline Per 10 years increase & 0.8 & $-0.0 ; 1.6$ \\
\hline \multicolumn{3}{|l|}{ Gender } \\
\hline Male vs. female & 2.9 & $-1.5 ; 6.2$ \\
\hline \multicolumn{3}{|c|}{ ASA classification: ASA I $=$ reference } \\
\hline ASA II & 5.1 & $1.6 ; 8.0$ \\
\hline ASA III & 11 & $7.1 ; 16$ \\
\hline ASA IV and V & 0.7 & $-7.9 ; 46$ \\
\hline \multicolumn{3}{|l|}{ Mode of surgery } \\
\hline Emergency vs. elective & 5.9 & $2.6 ; 10$ \\
\hline \multicolumn{3}{|c|}{ Indication for surgery: noninflammatory $=$ reference } \\
\hline Inflammatory & 8.6 & $5.0 ; 13$ \\
\hline Other & -0.8 & $-10 ; 16$ \\
\hline \multicolumn{3}{|l|}{$\begin{array}{l}\text { Intraoperative } \\
\text { cholangiography }\end{array}$} \\
\hline Yes vs. no & 5.4 & $-3.0 ; 15$ \\
\hline \multicolumn{3}{|l|}{ Intraoperative adhesiolysis } \\
\hline Yes vs. no & 2.1 & $-4.9 ; 18$ \\
\hline Intercept & 70 & $62 ; 76$ \\
\hline
\end{tabular}

The intercept corresponds to the median operative time and its $95 \%$ CI of a reference patient, i.e., a patient with all covariates in the reference group (female ASA I patient with mean age 54 years, elective surgery of a noninflammatory gallbladder operated by a resident with neither cholangiography nor adhesiolysis). To calculate the median operative time (the $95 \%$ CI would require more calculations) for any other combination, the estimated median difference of the corresponding covariate has to be added to the intercept. Example: male ASA III patient aged 64 years with an emergency cholecystectomy operated by a senior consultant because of an inflammatory disease and an intraoperative cholangiography would need: $70+$ $(-18)+0.8+2.9+11+8.6+5.4=80.7 \mathrm{~min}$ resulted in a $28 \min (95 \%$ confidence interval (CI), 10-35) shorter procedure. With minute costs of CHF27.9, this yielded mean incremental expenses of CHF781.2 (279976.5) per teaching case. On the basis of the minute costs in the university hospital, this meant incremental expenses of CHF975.1 (348.25-1218.88). Considering the average currency rate of CHF1.5878 per $€$ in the years 2005 until 2008, this corresponds to incremental costs of $€ 492(159 ; 615)$ for the reference hospital [17]. A more detailed analysis, including the different range of possible gratifications for SC or AS, is displayed in Fig. 4 and Table 4.

The approximate reimbursement for an uncomplicated cholecystectomy in Switzerland under Swiss DRG will be CHF7562 (€4763), meaning a deficit of more than $10 \%$ per case with tutorial assistance even in the case of higher gratifications for faculty members [18].

\section{Discussion}

This is the first large, multicenter study that quantifies the costs of operative training in the OR and shows that it results in a relevant deficit per case of approximately $10 \%$ for the teaching institution.

Earlier single-institution studies on operative times in case of tutorial assistance (without controlling for possible confounders) revealed comparable results but were not able to specify the costs. Prolonged operative times for different teaching operations were reported by Babineau and others. The time differences tended to increase with the complexity of the procedure $[6,12,19,20]$. Only two authors performed time-cost analysis: Harrington et al. found costs for one assisted anastomosis of US $\$ 1,457$ for laparoscopic enteroenterostomy in bariatric surgery [21]. Koperna analyzed hernia repair and LC as teaching operations; he found highest costs in unsupervised, young, board-certified surgeons (JC) [12]. Two, recent, comparative studies of patient care with or without residents focused on extra costs due to involvement of residents. These investigations showed higher costs due to a longer hospital stay and higher expenses for pharmacy, radiology, and central supply in the group treated by residents $[10,11]$.

In the light of these earlier findings, this investigation has three relevant results. First, operative training is a relevant cost factor. In reimbursement systems of public health care that deny coverage for this training expense, institutions without training commitments have a relevant competitive advantage because they can account same rates with lower costs. High costs for surgical training are probably a main reason for scarce training capacity even nowadays and may lead to further reduction of tutorial assistances in case of increased competition in healthcare markets. Secondly, the study shows a remarkably low 
Table 4 Operating room costs for laparoscopic cholecystectomy depending on senior consultants' salaries and operative team composition

\begin{tabular}{llllll}
\hline $\begin{array}{l}\text { Salary of senior } \\
\begin{array}{l}\text { consultant/ a } \\
(€)\end{array}\end{array}$ & $\begin{array}{l}\text { OR costs R } \\
\text { with JC }(€)\end{array}$ & $\begin{array}{l}\text { OR Costs JC with SC as first } \\
\text { assistant based on } 60 \mathrm{~h} / \text { week } \\
\text { of SC }\end{array}$ & $\begin{array}{l}\text { OR costs SC with R } \\
\text { based on } 60 \text { h/week of } \\
\text { SC }(€)\end{array}$ & $\begin{array}{l}\text { OR costs SC with R } \\
\text { based on } 80 \text { h/week of } \\
\text { SC }(€)\end{array}$ & $\begin{array}{l}\text { OR costs SC with JC } \\
\text { based on } 60 \mathrm{~h} / \text { week of } \\
\text { SC }(€)\end{array}$ \\
\hline 94,470 & 1405 & 1415 & 1048 & 1040 & 1061 \\
125,960 & 1405 & 1431 & 1060 & 1048 & 1073 \\
157,451 & 1405 & 1446 & 1071 & 1057 & 1084 \\
188,941 & 1405 & 1461 & 1083 & 1066 & 1096 \\
220,431 & 1405 & 1476 & 1094 & 1074 & 1107 \\
251,921 & 1405 & 1491 & 1106 & 1083 & 119 \\
283,411 & 1405 & 1507 & 1117 & 1091 & 1130 \\
314,901 & 1405 & 1522 & 1128 & 1100 & 1141 \\
629,802 & 1405 & 1674 & 1242 & 1185 & 1255 \\
\hline
\end{tabular}

$O R$ operating room; $R$ resident; $J C$ junior consultant; $S C$ senior consultant; $A S$ attending surgeon

proportion of teaching operations for residents concerning laparoscopic cholecystectomy. Residents operated on only $28 \%$ of the eligible patients. Taking into account that laparoscopic cholecystectomy is widely seen as a teaching operation, it is apparent that $72 \%$ of the operations are missed for surgical training [2, 6, 8, 9, 12, 22-24]. In the light of working hour restrictions and repeatedly stated concerns about decreasing quality of surgical training, reduction of these lost operations could lead to earlier surgical excellence in the career of young surgical residents [25].

Last but not least, the study shows a possible effect of this limited access to surgical training for residents: operative times between residents and junior consultants do not significantly differ. Only at the stage of consultant or attending surgeon, the learning curve for the operation seems to be accomplished, which results in a decrease in operative times of 10 to $35 \mathrm{~min}$. One could conclude that

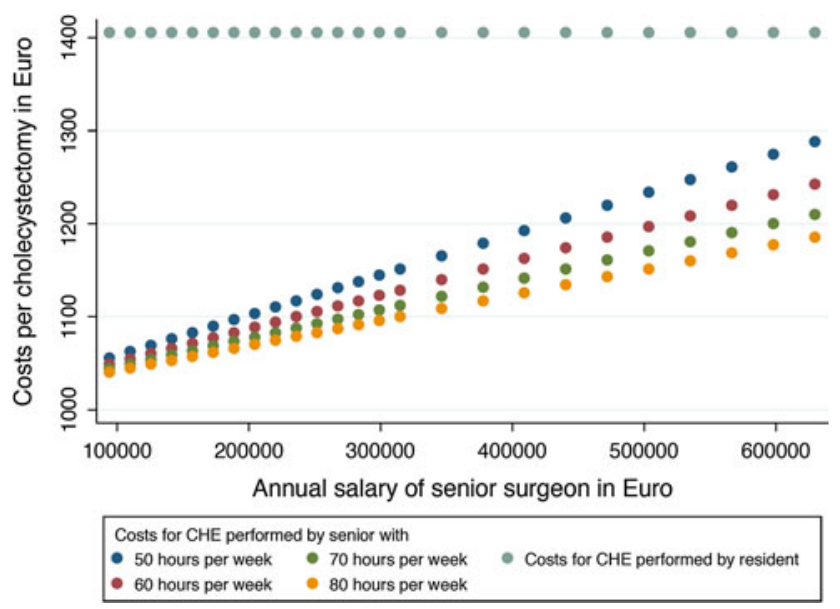

Fig. 4 Operating room costs per laparoscopic cholecystectomy depending on operating surgeon (resident with junior consultant versus senior consultant with resident) and salary of senior consultant due to the fact of missed training opportunities during residency, the young surgeon needs to continue training at the stage of chief resident or junior consultant reflected by the longer operative times at this stage. Given the fact that laparoscopic interventions performed by surgeons have become more and more complex during the past decade (laparoscopic colorectal surgery, NOTES, SILS, etc.), this delay in surgical training seems not reasonable [26].

Because the public has a vital interest in a functioning healthcare system in the future, which implies good and sound surgical training of young surgeons, it should be reasonable to pay for it [27]. In times of shortage of medical offspring, one has to abandon the idea of covering these costs by lower wages for surgical residents; however, the present study shows that the costs are too high, which would lead to noncompetitive low salaries for young surgeons compared with other specialties. Informal reductions in salary by extension of working hours are limited by recent working hour restrictions for medical staff in the United States and Europe [25, 28].

Another common model of cost reduction is implicit prioritization: one exclusive resident receives formation, whereas his colleagues just work though they have the same formal position (as a resident). The selection criteria stay subtle. This situation seems common in surgical departments in Germany or Switzerland as reported in annual reports on quality of training [29, 30]. This would however need a clear communication of who receives actually such a training position. An alternative would be to have more residents in surgical departments who do not opt for a surgical career but just for getting some insights into surgery during a limited period of time, such as 1 year. Neither low salaries nor other informal models of cost reduction will achieve a sustainable funding of surgical education. Deterioration of working conditions will aggravate the shortage of surgical offspring. 
So, the results of this study underline the relevance of training-related expenses for teaching hospitals and especially for surgical specialties. Because health care in almost all industrialized countries has become at least partly a competitive market in the past decades, economic disadvantages for teaching institutions will lead to a reduction in training capacity. To avoid this tendency and to ensure well-trained surgical offspring under these circumstances, reimbursements for high training costs in surgical specialties should be implemented. Because the present study has been limited only to one common teaching operation and cost figures were only available from two institutions, studies investigating all economic aspects of surgical training will be necessary to make justifiable recommendations for reimbursement for these training expenses.

Acknowledgments The authors thank Luzi Rageth and the Swiss Association for Quality Management in Surgery (AQC) for their support in this investigation.

Disclosures Drs. von Strauss, Dell-Kuster, Mechera, and Langer, and Prof. Rosenthal have no conflicts of interest or financial ties to disclose.

\section{References}

1. Bartowski R (2009) Problem DRG: bleibt die ärztliche Weiterbildung auf der Strecke? Swiss Knife 3:8-10

2. Bridges M, Diamond DL (1999) The financial impact of teaching surgical residents in the operating room. Am J Surg 177:28-32

3. Frank S (2009) Financing graduate medical education. Nat Clin Pract Neurol 5:58-59

4. Webb TP, Brasel KJ, Redlich PN, Weigelt JA (2010) Putting a price on education: hours and dollars for a general surgery curriculum. Am J Surg 199:126-130

5. Glauser R (2010) Finanzierung der ärztlichen Weiterbildung. VSAO J 9:8

6. Babineau TJ, Becker J, Gibbons G, Sentovich S, Hess D, Robertson S et al (2004) The "cost" of operative training for surgical residents. Arch Surg 139:366-369 discussion 369-370

7. Chung RS (2005) How much time do surgical residents need to learn operative surgery? Am J Surg 190:351-353

8. Deziel DJ, Millikan KW, Staren ED, Doolas A, Economou SG (1993) The impact of laparoscopic cholecystectomy on the operative experience of surgical residents. Surg Endosc 7:17-21

9. Haji A, Khan A, Haq A, Ribeiro B (2009) Elective laparoscopic cholecystectomy for surgical trainees: predictive factors of operative time. Surgeon 7:207-210

10. Hwang CS, Pagano CR, Wichterman KA, Dunnington GL, Alfrey EJ (2008) Resident versus no resident: a single institutional study on operative complications, mortality, and cost. Surgery 144:339-344

11. Hwang CS, Wichterman KA, Alfrey EJ (2010) The cost of resident education. J Surg Res 163:18-23

12. Koperna $\mathrm{T}$ (2004) How long do we need teaching in the operating room? The true costs of achieving surgical routine. Langenbecks Arch Surg 389:204-208
13. Hutter MM, Kellogg KC, Ferguson CM, Abbott WM, Warshaw AL (2006) The impact of the 80-hour resident workweek on surgical residents and attending surgeons. Ann Surg 243:864-871 discussion 871-875

14. Knapp R (2002) Financing graduate medical education and limiting resident work hours: a political assessment. Am J Surg 184: $187-195$

15. Telser H, Leukert K (2009) Finanzierung der ärztlichen Weiterbildung aus ökonomischer Sicht. Available at: http://www.poly nomics.ch/dokumente/Polynomics_Finanzierung-aerztl-WB_2009. pdf. Accessed 2 May 2011

16. Steyerberg EW (2009) Dealing with missing values. In: Gail M, Krickeberg K, Samet J, Tsiatis A, Wong W (eds) Clinical prediction models. Springer, New York, pp 113-136

17. Credit Suisse (2008) Devisendurchschnittskurse 2005-2008. Available at: https://www.credit-suisse.com/ch/unternehmen/kmu grossunternehmen/doc/devisendurchschnittskurse_2008_de.pdf. Accessed 6 Jan 2011

18. Swiss DRG Casemix Office (2011) webgrouper.swissdrg.org. Available at: https://webgrouper.swissdrg.org. Accessed 23 June 2011

19. Kauvar DS, Braswell A, Brown BD, Harnisch M (2006) Influence of resident and attending surgeon seniority on operative performance in laparoscopic cholecystectomy. J Surg Res 132:159-163

20. Z'graggen K, Wehrli H, Metzger A, Buehler M, Frei E, Klaiber C (1998) Complications of laparoscopic cholecystectomy in Switzerland. A prospective 3-year study of 10,174 patients. Swiss Association of Laparoscopic and Thoracoscopic Surgery. Surg Endosc 12:1303-1310

21. Harrington DT, Roye GD, Ryder BA, Miner TJ, Richardson P, Cioffi WG (2007) A time-cost analysis of teaching a laparoscopic entero-enterostomy. J Surg Educ 64:342-345

22. Sefr R, Ochmann J (1995) Our experience with early integration of laparoscopic cholecystectomy in surgical residency training. Surg Endosc 9:902-904

23. Shaikh IA, Sanjay P, Joga K, Yalamarthi S, Daniel T, Amin AI (2009) Are we performing enough emergency laparoscopic cholecystectomies? An experience from a district general hospital. Int J Surg 7:482-484

24. Wang WN, Melkonian MG, Marshall R, Haluck RS (2001) Postgraduate year does not influence operating time in laparoscopic cholecystectomy. J Surg Res 101:1-3

25. Businger A, Guller U, Oertli D (2010) Effect of the 50-hour workweek limitation on training of surgical residents in Switzerland. Arch Surg 145:558-563

26. Allemann P, Schafer M, Demartines N (2010) Critical appraisal of single port access cholecystectomy. Br J Surg 97:1476-1481

27. O'Shea JS (2010) Individual and social concerns in American surgical education: paying patients, prepaid health insurance, Medicare and Medicaid. Acad Med 85:854-862

28. Jarman BT, Miller MR, Brown RS, Armen SB, Bozaan AG, Ho GT et al (2004) The 80-hour work week: will we have lessexperienced graduating surgeons? Curr Surg 61:612-615

29. Orlowa P, Siegrista M, Giger M (2007) Die wichtigsten Resultate der Umfrage 2006 bei Assistenzärztinnen und Assistenzärzten. Schweiz Ärzteztg 88:633-642

30. van der Horst K, Siegrist M, Orlow P, Giger M (2010) Residents' reasons for specialty choice: influence of gender, time, patient and career. Med Educ 44:595-602 